\title{
MÉTODOS E PROCESSOS DE INTERPRETAÇÃO
} CONSTITUCIONAL

\author{
Guilherme Rodrigues
}

Erro de gráfica: faltando as págs. 146, 147, 150, 151, 154 e 155 
através de critérios científicos. KELSEN desmistifica a tentativa de se encontrar uma fórmula única e infalível de interpretação, dizendo o seguinte: "Não há absolutamente qualquer método - capaz de ser classificado como de Direito positivo - segundo o qual, das várias significações verbais de uma norma, apenas uma possa ser destacada como 'correta' - desde que, naturalmente, se tratem de várias significações possíveis: possíveis no confronto de todas as outras normas da lei ou da ordem jurídica. (. . .) Todos os métodos de interpretação até hoje elaborados conduzem sempre a um resultado apenas possível, nunca a um resultado que seja o único correto " (ob. cit., p. 468).

3. A interpretação constitucional não foge aos princípios e métodos da hermenêutica geral. No entanto, possui algumas características próprias e que jamais podem ser esquecidas pelo hermeneuta, em face da natureza especial da Constituição e sua posição ímpar na pirâmide do ordenamento jurídico.

A utilidade básica da interpretação constitucional traduz o ideal de atualização do texto da Lei Maior em face de mudanças inevitáveis da realidade a que ele se prende e à qual deve servir. PAULO BONAVIDES, citando SANTI ROMANO, afirma que o emprego da hermenêutica jurídica faz possível a alteração do sentido da norma constitucional, sem necessidade de substituí-la expressamente ou alterá-la pelas vias formais da emenda constitucional (ob. cit., ps. 293 e 294). A tarefa da substituição ou alteração pela via constituinte originária ou derivada sempre é muito complexa e demanda extrema mobilização social e política.

Exemplo significativo desse processo de adaptação pela via hermenêutica é o sistema constitucional norte-americano, cuja Lei Fundamental possui quase 200 anos de existência e, ao longo desse tempo todo, vem sendo adequada à realidade cotidiana através interpretação da Suprema Corte daquele país.

Assim, mediante a interpretação de suas normas, as constituições rígidas mantêm sua vida como instrumentos de progresso, segurança e justiça social, amoldando-se naturalmente ao contexto nacional sobre o qual se erigem. Ao contrário, a constituição que não sofra esses ajustes acaba fossilizando-se no tempo e, fatalmente, termina desaparecendo vítima de brusco e violento choque revolucionário.

\section{COORDENADAS PECULIARES.}

4. O Direito Constitucional é essencialmente um direito de conteúdo político. Conquanto, sob o ponto de vista formal, a Constituição escrita seja uma Carta jurídica, o que vem trazer certa segurança aos princípios ali expressos, o seu conteúdo, assim como o seu ato de criação, são eminentemente políticos.

$\mathrm{O}$ intérprete deve ter em conta certas peculiaridades inerentes às normas constitucionais. Assim, independentemente do método ou processo que utilize, certas premissas estarão constantemente atuantes 
e precisam ser consideradas. Tais premissas traduzem-se em coordenadas de interpretação constitucional, que podem ser resumidas em: a) inicialidade fundamental; b) conteúdo essencialmente político; c) linguagem sintética e coloquial; d) rigidez formal; e) predominância de normas de estrutura ou de organização - destinadas ao legislador.

5. A inicialidade fundamental impõe que os preceitos constitucionais sejam tratados como de superior categoria hierárquica e fundamento de validade para toda a ordem jurídica. Não sofrem, portanto, subordinação a qualquer outro ramo do ordenamento e tampouco a qualquer outra situação jurídica pretérita. Sob este prisma, as normas constitucionais são a própria razão de ser das demais situações jurídicas.

6. O conteúdo essencialmente político da Constituição implica em que suas normas, quer destinando-se à organização e controle do Poder, quer estabelecendo e conferindo identidade aos direitos e garantias individuais, devem ser interpretadas segundo essas finalidades. Isto faz com que elementos assistemáticos incidam no processo de interpretação. Havendo conteúdo político ínsito à Lei Fundamental, é inevitável que os aspectos ideológicos devam ser enfrentados pelo intérprete, se este não quiser empreender atividade formal e estéril.

Compondo o mosaico político das constituições, inscrevem-se os valores culturais, éticos, sociais e até morais, que sejam adotados por um povo em determinada época de sua história. Tais fatores, de formulação concreta na vida social, adquirem significado real e influem de maneira decidida as relações e o processo político das sociedades, devendo ser atendidos pelo intérprete.

7. Outro fator essencial, que influi como premissa, é a linguagem sintética e coloquial do texto da Constituição. Sendo uma carta destinada a todos os cidadãos, não pode vir vazada em termos de compreensão estrita a um grupo de iniciados numa qualquer semântica especial; mas deve apresentar - e na realidade apresenta - uma estrutura de sintaxe e vernáculo comum e acessível aos padrões gerais da linguagem.

Por outro lado, na medida em que se destina a assentar os princípios reitores de todo ordenamento jurídico, a Constituição não vai a pormenores e, simplesmente, limita-se a apontar genérica, mas seguramente, os princípios maiores. Esse aspecto é enfatizado por CELSO RIBEIRO BASTOS e CARLOS AYRES DE BRITO, que afirmam: "precipuamente voltada para a indicação de fins a alcançar e deveres a cumprir (por parte dos órgãos e agentes públicos), a Lei Suprema costuma omitir-se quanto à explicitação dos correspectivos meios. Daí a formulação da célebre doutrina dos poderes implícitos, de matriz norte-americana, que tem em Story um de seus qualificados arautos." (Interpretação e Aplicabilidade das Normas Constitucionais, ed. Saraiva, São Paulo, 1982, p. 23). Além do exemplo citado, ainda na construção da jurisprudência da Suprema Corte norte-americana, de formulação mais recente que os poderes implícitos, temos os penumbral rights, dentre os quais avulta o direito à privacidade. Exatamente considerando que a linguagem constitucional é genérica e não técnica, a Suprema Corte, 
legis, a mens legislatoris, enfim, a vontade da lei assim que ela nasce); c) lógico (considera a vontade atual da norma, no momento em que ela se vai aplicar, enfim, a ratio legis em contrapartida à occasio legis, e a mens legis em oposição à mens legislatoris).

O método lógico pode, ainda, ser decomposto em diversas variantes, estando entre as mais significativas: a) sistemática (coerência da norma com o sistema jurídico em que ela se inscreve); b) histórico-teleológica, evolutiva ou progressiva (a mais amplamente utilizada indaga a finalidade atual em face do momento presente da aplicação, levando em conta a evolução da norma e aspectos sociais, políticos, éticos, morais, ideológicos, etc.); c) voluntarista (atribuída a KELSEN parte do pressuposto de que existe mais de uma alternativa à interpretação, todas limitada por uma moldura geral, que seria a norma. Ao intérprete, segundo sua vontade, cabe escolher qual dos resultados possíveis deve ser aplicado); d) do direito-livre (entrega ao intérprete toda discricionariedade, sem limites e absoluta, na fixação do conteúdo normativo).

Como não exegéticos mencionem-se: a) Integrativo ou científicoespiritual. Surgiu na Alemanha, durante este século, e sua formulação deve-se a SMEND. Buscou uma reação aos padrões exegéticos manipulados por juristas bismarckianos de modo formal-positivista. Parte do pressuposto de que a Constituição há de ser interpretada como um todo e de que o Direito Constitucional não pode ser decomposto num agregado de normas e institutos isolados entre si e alheios à realidade. Assim, a partir da realidade da vida, da concretude da existência, compreendida pelo que tem de espiritual, através de um processo unitário, renovador da própria realidade, integra-se a norma no conjunto da Constituição (PAULO BONAVIDES, ob. cit., ps. 317 e ss.) Note-se como tal método possui inúmeros pontos de contato com o lógico-sistemático $\mathrm{e}$ o progressivo. b) Concretização - Este método gravita em redor de três princípios básicos: a norma que se vai concretizar, a compreensão prévia do intérprete e um problema concreto a ser resolvido. Onde houver obscuridade, o intérprete virá determinar o conteúdo material da Constituição, examinado-o diante de um problema concreto e a partir de uma compreensão prévia e não arbitrária. Assim, para esse método, a Constituição não é um sistema hierárquico-axiológico (segundo os integrativistas) e nem lógico-axiomático (para os positivistas), mas deve ser ater ao princípio da estabilidade social, que será garantida pela satisfação das necessidades institucionais, políticas, sociais, ideológicas, etc., através do processo de interpretação da Lei Fundamental. A cada momento a solução necessária e adequada será concretizada, segundo este método (PAULO BONAVIDES, ob. cit., p. 321 e ss.).

Estes dois últimos métodos surgiram na Alemanha, durante este século, para corrigir os excessos do espírito positivista, que não hesitava em sacrificar as mais profundas realidades sociais e políticas no altar do exercício dogmático de uma lógica fria de dissecação formal da Constituição, como se o substrato nacional nada significasse. 
14. Seja, afinal, qual for o método ou processo hermenêutico utilizado, deve-se ter em conta que atitudes excessivamente liberais de interpretação, em matéria constitucional, podem levar ao autoritarismo do intérprete, que passaria, em tais casos, a agir como se o próprio poder constituinte originário the pertencesse, isto é, sem conhecer limite algum. Tal colocação afronta o princípio de segurança que deve inspirar a tarefa de aplicação das normas jurídicas. Nesse caso aberrante, estaríamos diante de nítida usurpação de funções por parte de tal espécie de hermenêutica discricionária.

$\mathrm{O}$ reverso da moeda também é válido. Uma dogmática e um formalismo excessivos inibiram a evolução e necessária adaptação do texto constitucional ao progresso e câmbio social. Em decorrência, a Lei Fundamental seria logo transformada em documento antiquado e opressor, constituindo-se em relicário, cuja teimosia em não se atualizar ou abrir espaço para a demanda da evolução, terminaria desestabilizando toda a ordem jurídica, que fatalmente sofreria um golpe revolucionário. 15. Caso o resultado da atividade de interpretação iguale-se ao significado literal da norma, diz-se que a interpretação é declarativa, quanto à sua extensão. Quando for ampliado, fala-se em interpretação extensiva; quando diminuido, será restritiva. Se o significado literal for negado pela interpretação, ela será conceituada como ab-rogànte.

Em matéria constitucional admitem-se resultados declarativos, extensivos e restritivos. A ab-rogação de normas constitucional pela via hermenêutica, em princípio, não é possível. Para tanto, o intérprete teria de estar investido por poderes constituintes originários, pois só a tal Poder é dado revogar seus atos. Assim, para os sistemas de constituições rígidas, pelo menos, não se admitiria esse modo de ab-rogação. Somente quando a norma apresentasse visível e flagrante contradição com o restante da própria Constituição é que poderia se admitir sua ab-rogação. Neste caso, o intérprete não estaria exercendo poder constituinte originário, mas declarando uma impossibilidade colocada pelo próprio constituinte, ou seja, a insubsistência de preceito contraditório ao resto do Diploma. Mas a admissão de tal hipótese leva a supor que o constituinte originário possa ser vítima de contradição.

16. Retidão e certeza do direito são aspectos que devem ser atendidos por uma correta hermenêutica. Assim, o intérprete deve considerar a busca do sentido mais justo e oportuno da norma (retidão) e zelar para que o resultado de seu ato mantenha uniformidade e eqüidade com as aplicações anteriores do direito (certeza). Uniformidade que não significa identidade, o que transformaria o direito em algo estático e imutável, mas que tem o sentido de coerência e segurança, que se antepõe às mutações bruscas do arbítrio inaceitável.

17. Há duas vertentes fundamentais em matéria hermenêutica. A primeira consiste na interpretação que cria direito, isto é, aquela processada por órgão encarregado da aplicação das normas. E a outra, aquela que não cria dirieto, ou seja, as análises e conclusões da ciência do direito, da doutrina, e a interpretação que cada indivíduo dá às normas 
tampouco, entendida quanto aos direitos e garantias individuais que a Carta assegura e admite, explícita e implicitamente.

21. Outro problema é saber se existe um costume constitucional e se ele pode ou não ser aplicado em se tratando de interpretação constitucional. GEORGES BURDEAU responde afirmativamente, mas não admite que o costume possa derrogar o texto ou sobrepor-se ao mesmo. $\mathrm{O}$ autor acrescenta que o reconhecimento do costume é importante e será muito útil "pour ajouter à un texte insuffisant ou pour l'interpréter, mais non pour le corrigier". (Droit Constitutionnel et Institutions Politiques, ed. L. G. D. J., Paris, 1980, p. 66).

22. A solução das lacunas no texto da Lei Maior demanda o concurso da hermenêutica constitucional. Com efeito, neste campo influem decididamente os processos de interpretação, já que os claros eventuais da Carta Magna não podem ser resolvidos por elementos jurídicos infraconstitucionais, dada a inicialidade da Lei Maior sobre o restante do ordenamento jurídico. Não procede, tampouco, que o constituinte originário, ao não inscrever certa matéria no texto constitucional, tenha-na deixado para os níveis do legislador ordinário ou constituinte derivado. Isto pode acontecer, mas não se dá necessariamente. O exemplo do controle da constitucionalidade das leis pela Suprema Corte norte-americana é caso típico. Esse poder não estava expresso na Constituição e tampouco em qualquer de suas emendas (situação que persiste até hoje). No entanto, ele vem sendo exercido desde 1803, o que reforça a idéia da construction. 